\title{
Cannabidiol (CBD) Oil Does Not Display an Entourage Effect in Reducing Cancer Cell Viability in vitro
}

\author{
Wesley M. Raup-Konsavage ${ }^{\text {a }}$ Nurgul Carkaci-Salli ${ }^{a} \quad$ Kelly Greenland ${ }^{\text {b }}$ \\ Robert Gearhart $^{\mathrm{b}}$ Kent E. Vrana ${ }^{\mathrm{a}}$ \\ aDepartment of Pharmacology, Penn State College of Medicine, Hershey, PA, USA; \\ bKeystone State Testing, LLC, Harrisburg, PA, USA
}

\section{Keywords}

CBD oil · Cannabidiol $\cdot$ Melanoma $\cdot$ Colorectal cancer .

Glioblastoma $\cdot$ Entourage effect

\begin{abstract}
Introduction: Several studies have found that cannabinoids, particularly delta-9-tetrahydrocannabinol and cannabidiol $(C B D)$, have the ability to reduce cancer cell viability. An ongoing debate regarding the use of medical Cannabis revolves around the effectiveness of pure compounds versus intact plant material for treatment. Proponents for the use of intact plant material or botanical extracts argue that there is a synergistic effect between the different cannabinoids, terpenoids, and flavonoids; this is commonly referred to as the "entourage effect." Our study was designed to test the validity of the proposed entourage effect in a narrow application using a cancer cell viability model. Materials and Methods: Six cancer cell lines, from 3 different types of human cancer were treated with $10 \mu \mathrm{m}$ pure CBD or $10 \mu \mathrm{M}$ CBD from hemp (Cannabis sativa) oil (obtained from 3 different commercial sources) for $48 \mathrm{~h}$, and cell viability was measured with the MTS assay. Dose-response curves were then performed to compare the potencies of pure CBD to CBD oils. CBD concentrations were independently confirmed in the commercial
\end{abstract}

karger@karger.com www.karger.com/mca

Karger"

GOPEN ACCESS
(C) 2020 The Author(s)

Published by S. Karger AG, Basel

This article is licensed under the Creative Commons AttributionNonCommercial-NoDerivatives 4.0 International License (CC BYNC-ND) (http://www.karger.com/Services/OpenAccessLicense). Usage and distribution for commercial purposes as well as any distribution of modified material requires written permission. oils, and cannabinoid and terpene composition were also compared. Results: CBD $(10 \mu \mathrm{M})$ was able to reduce cell viability in 3 of the 6 cell lines tested, and this was found to be cell line specific and not specific to select cancers. None of the CBD oils tested were able to reduce viability to a greater extent than that of pure CBD. Additionally, dose-response curves found lower $I C_{50}$ values for pure $C B D$ compared to the most potent $C B D$ oil tested. Interestingly, some oils actually appeared to protect cancer cells from the effects of CBD. Conclusions: We found that pure CBD was as potent or more potent at reducing cancer cell viability as the most potent oil tested, suggesting that there is no "entourage" effect under these specific in vitro conditions.

(c) 2020 The Author(s)

Published by S. Karger AG, Basel

\section{Introduction}

The Cannabis sativa plant (marijuana and hemp) has a long history of use in medical therapy. There are records of the use of this plant dating back almost 5,000 years ago in China to treat gout, malaria, constipation,

Wesley M. Raup-Konsavage and Nurgul Carkaci-Salli authors contributed equally. 
rheumatism, and other conditions [1]. Extracts of C. sativa contain a large number of phytochemicals such as terpenes and flavonoids, as well as a unique class of molecules known as cannabinoids. There are over 100 different known cannabinoids, with the 2 most abundant being delta-9-tetrahydrocannabinol (THC) and cannabidiol (CBD). Unlike THC, CBD does not produce euphoria but has been shown to modulate the activity of THC and have anti-inflammatory and analgesic activities [2-4].

There is a growing trend globally for the use of medical cannabis. THC, in the synthetic form known as dronabinol, has been FDA-approved to stimulate appetite and treat nausea patients with HIV/AIDS or undergoing chemotherapy [5-8]. More recently, CBD has been approved to treat pediatric seizure disorders in the US [9]. While studies using individual cannabinoids for the treatment of cancer have shown promise [10-13], proponents of medical marijuana argue that there is an additive effect between the various cannabinoids, terpenoids, and other compounds in C. sativa that increase the efficacy of the plant as a medicine, compared to the individual compounds [14-18]. This premise, that there is a synergistic activity of crude extracts, is known as the "entourage effect." However, this has not been widely studied scientifically and may prove to be restricted to selected situations. In the present study, we assessed the potential entourage effect in CBD-induced cancer cell death in vitro.

A number of studies have investigated the ability of phytocannabinoids to reduce cancer cell viability in breast cancer, colorectal cancer, glioblastomas (GBM), lung cancer, and a variety of other models. Several of these studies have found that CBD or THC can reduce cancer cell viability [10, 19-26]. Interestingly, 2 studies have shown the opposite effect - that these compounds can promote tumor growth as well $[27,28]$.

The objective of this study was to examine if CBD oils isolated from hemp (C. sativa) would be more potent in reducing cancer cell viability than pure CBD - thus supporting the concept of an "entourage" effect in this specific situation. Previously, we have shown that CBD had a very modest impact on the growth of select colorectal cancer cells (CRCs) [13], and we expanded those results here to identify any potential impact CBD has on melanoma or GBM cell growth as well. We did not find any additional efficacy in CBD oils as compared to pure $\mathrm{CBD}$ (when matched for CBD concentration).

\section{Methods}

\section{Cell Culture}

CRC lines (SW480 and HCT116) and melanoma cell lines (1205Lu and A375M) were grown in DMEM supplemented with $10 \%$ fetal bovine serum, $2 \mathrm{mM}$ GlutaMAX, $10 \mathrm{U} / \mathrm{mL}$ penicillin, 10 $\mu \mathrm{g} / \mathrm{mL}$ streptomycin, and $0.25 \mu \mathrm{g} / \mathrm{mL}$ amphotericin B. GBM cell lines (T98G and U87MG) were grown in DMEM supplemented, as above, but with the addition of $1 \mathrm{mM}$ sodium pyruvate and $1 \mathrm{x}$ nonessential amino acids (ThermoFisher; Waltham, MA, USA). Cells were cultured at $37^{\circ} \mathrm{C}$ in $5 \% \mathrm{CO}_{2}$. All cell lines had been obtained from the American Type Culture Collection and their identities confirmed by short tandem repeat DNA profiling by Genetica Cell Line Testing (Burlington, NC, USA). As noted throughout, experiments were conducted in the presence of fetal bovine serum as opposed to serum-deprived cells so as to better mimic the pharmacokinetic conditions of the cancer cell environment in vivo.

\section{Cell Treatment \& Viability Assay}

CRC cell lines were treated as previously described, except cells were seeded at a density of 10,000 cells/well [13]. Melanoma and GBM cells were seeded at a density of 7,500 cells/well and $12 \mathrm{~h}$ later treated with pure CBD (Cayman Chemical; Ann Arbor, MI, USA) or CBD oils containing an equivalent concentration of CBD (in addition to the other lower levels of the other constituents of the oil - e.g., cannabinoids, terpenes, and flavonoids). In all treatments, the DMSO was maintained at a constant $1 \%$. Oil manufacturers are not listed due to the lack of consent for disclosure. The MTS ((3-(4,5-dimethylthiazol-2-yl)-5-(3-carboxymethoxyphenyl)2-(4-sulfophenyl)-2H-tetrazolium), Biovision; Milpitas, CA, USA) assay was used to assess viability as previously described [13].

\section{Commercial CBD Oil Analysis}

Commercial CBD extracts were purchased, and their cannabinoid compositions confirmed by standard American Herbal Pharmacopeia methodologies [29] by a state-accredited cannabinoid testing laboratory (Keystone State Testing; Harrisburg, PA, USA). Briefly, $0.1 \mathrm{~g}$ of sample is dissolved in $20 \mathrm{~mL}$ acetonitrile (ThermoFisher; Waltham, MA, USA) and then placed in a ball mill grinder at 1,000 rpm for $1 \mathrm{~min}$. Subsequently, the sample was sonicated for $15 \mathrm{~min}$ and then filtered through $0.2 \mu \mathrm{m}$ filter. Samples were then analyzed by reverse phase HPLC using a Restek (State College, PA, USA) Raptor ARC C-18 column ( $2.7 \mu \mathrm{m}$ particle size, $150 \mathrm{~mm}, 4.6$ $\mathrm{mm}$ ID, and matching guard length $5 \mathrm{~mm}$ ), with mobile phase A: $1 \%$ phosphoric acid in water, B: $1 \%$ phosphoric acid in acetonitrile. Cannabinoids were detected by spectrometry at $220 \mathrm{~nm}$ (Shimadzu; Columbia, MD, USA) where instrument control, data acquisition, and integration were achieved with LabSolutions (Ver 5.87 SP1, Shimadzu), calibrated with a 7 point curve from $0.5 \mu \mathrm{g} / \mathrm{mL}$ to $100 \mu \mathrm{g} / \mathrm{mL}$ using an 11 compound cannabinoid certified reference material mixture (Shimadzu; Columbia, MD, USA).

Terpenes were extracted with methanol and analyzed by headspace in a Shimadzu 8050 GCMS-MS (Shimadzu; Columbia, MD, USA). A collection of 42 terpene compounds were used as calibration standards (CAN-TERP-MIX1H and CAN-TERP-MIX2H [Spex; Metuchen, NJ, USA]).

Dose Response Curves

Cells were treated as described above at varying concentrations of CBD or CBD Oil A (the most potent of the 3 oils based on viabil-
Med Cannabis Cannabinoids 2020;3:95-102 DOI: $10.1159 / 000510256$
Raup-Konsavage/Carkaci-Salli/

Greenland/Gearhart/Vrana 
ity analyses (Fig. 2)): 100, 56, 33, 18, 10, 3.3, 1.0, 0.33, and $0.1 \mu \mathrm{M}$. Viability was measured as described above and GraphPad Prism software (GraphPad Software; San Diego, CA, USA) was used to calculate $\mathrm{IC}_{50}$ values and to prepare semi-logarithmic dose-effect curves.

\section{Statistical Analysis}

For studies involving pure CBD (vs. control), the Student's $t$ test was used to determine statistical significance and a $p \leq 0.05$ was employed as the threshold for significance. For the studies involving the various CBD oils, an ANOVA was first performed followed by a Student's $t$ test, if appropriate, with the same threshold as above.

\section{Results}

\section{Ability of CBD to Reduce Cancer Cell Viability}

We previously reported that $\mathrm{CBD}$ was able to reduce the viability of some CRC lines; however, it was not as potent as synthetic cannabinoids at reducing cell viability [13]. In the present studies, we selected 2 lines that had different sensitives in the previous study. Cells were treated with CBD at a concentration of $10 \mu \mathrm{M}$ for $48 \mathrm{~h}$ and viability was measured by MTS assay. We confirmed our previous results in CRC cells (Fig. 1a) and expanded our finding to melanoma (Fig. 1b) and GBM (Fig. 1c) cell lines. CBD had an effect on SW480 CRC cells, 1205Lu melanoma cells, and T98G GBM cells and did not significantly reduce viability in the other cell lines tested. The results of the MTS assay were confirmed in select cell lines by trypan blue staining and cell counting (data not shown). These data suggest that CBD is not inducing apoptosis, but restricting growth, as the percentage of dead cells was not significantly different between vehicle and CBD-treated cells. This was consistent with our previous report that $\mathrm{CBD}$ is not universally efficacious in reducing cancer cell viability.

\section{Selection of CBD Oils}

Efforts were made to select high-quality oils for this study. Oils were selected based upon the following criteria: (1) unflavored oils to avoid added chemicals; (2) the company provided third party analysis of composition; (3) the company tracked lot numbers; and (4) the company was highly reviewed by independent online sources. Three oils that met these criteria were selected for study, hereafter referred to as Oil A, Oil B, and Oil C.

\section{Characterization of CBD Oils}

Oils for this study were specifically selected because the companies provided third party verification of their

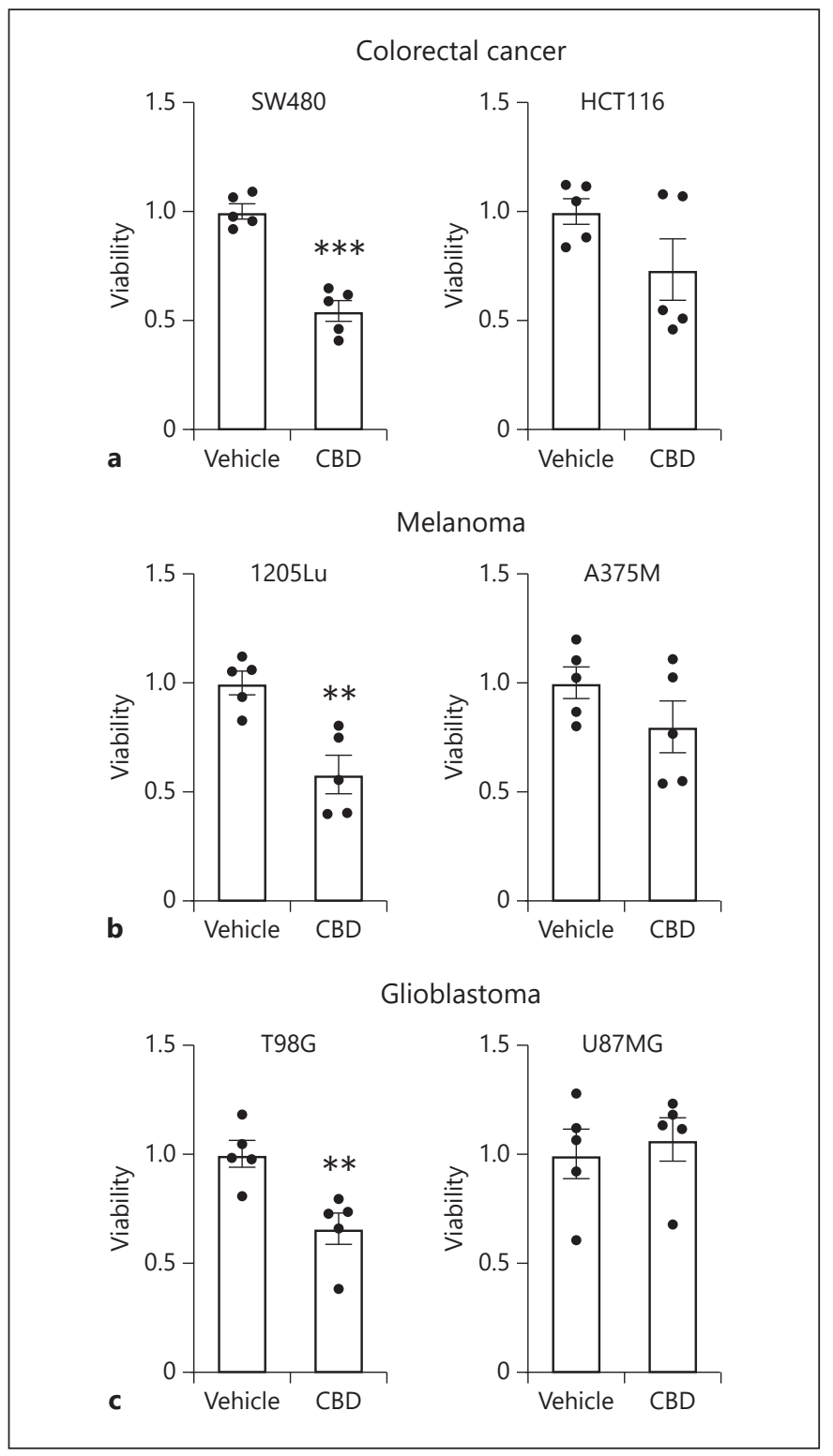

Fig. 1. CBD and cancer cell viability. Cell viability was measured by MTS assay $48 \mathrm{~h}$ after treatment with $10 \mu \mathrm{M} \mathrm{CBD}$ : colorectal cancer cell lines (SW480 and HCT116 cells) (a); melanoma cell lines (1205Lu and A375M) (b); and GBM cell lines (T98G and U87MG) (c). Results are normalized to DMSO vehicle. Error bars are SEM; ${ }^{* *} p \leq 0.01,{ }^{* * *} p \leq 0.001$. CBD, cannabidiol; GBM, glioblastoma.

content; however, we verified their content through independent confirmatory testing. The testing laboratory was blinded to the identity of the oils. Only minor discrepancies were observed between the reported values and our analysis (Table 1; each oil was within $8 \%$ of their reported CBD concentration upon independent testing). The THC content for all 3 oils was below $0.3 \%$ (based on total mass 
Table 1. Cannabinoid composition of CBD oils

\begin{tabular}{|c|c|c|c|c|c|c|}
\hline \multirow[t]{2}{*}{ Cannabinoid } & \multicolumn{3}{|c|}{ Reported by company, mg/mL } & \multicolumn{3}{|c|}{ Independent testing, $\mathrm{mg} / \mathrm{mL}$} \\
\hline & oil A & oil B & oil C & oil A & oil B & oil C \\
\hline CBD & 54.59 & 51.90 & 35.22 & 54.42 & 47.52 & 32.36 \\
\hline $\mathrm{CBC}$ & 2.09 & 2.72 & 1.72 & 2.35 & 2.70 & 1.74 \\
\hline CBDA & 0.23 & n.r. & 0.33 & 0.28 & 0.34 & $<\operatorname{lod}$ \\
\hline CBDV & 0.67 & 0.29 & n.r. & 1.00 & 0.37 & 0.33 \\
\hline CBG & 0.93 & 2.47 & 0.29 & $<\operatorname{lod}$ & 2.36 & $<\operatorname{lod}$ \\
\hline $\mathrm{CBN}$ & 0.24 & 0.04 & 0.09 & 0.35 & $<\operatorname{lod}$ & $<\operatorname{lod}$ \\
\hline THC & 1.32 & 2.02 & 1.54 & 1.16 & 1.73 & 1.73 \\
\hline
\end{tabular}

CBD, cannabidiol; THC, delta-9-tetrahydrocannabinol; lod, limits of detection; n.r., not reported. Shown are the results reported by the commercial source of the $\mathrm{CBD}$ oil and the results of our testing of cannabinoid composition for each of the $3 \mathrm{CBD}$ oils.

Table 2. Terpene composition of CBD oils

\begin{tabular}{llll}
\hline Terpene, ppm & Oil A & Oil B & Oil C \\
\hline $\begin{array}{llll}\text { B-Farnesene } \\
\text { Trans caryophyllene }\end{array}$ & 3,790 & 1,635 & $<$ lod \\
a-Humulene & 728 & 750 & 301 \\
$\begin{array}{l}\text { (-)- } \alpha \text {-Bisabolol } \\
\text {-Farnesene }\end{array}$ & 272 & 317 & 170 \\
& $<$ lod & 192 & $<$ lod \\
\hline
\end{tabular}

CBD, cannabidiol; lod, limits of detection. Shown are the results of our testing of terpene composition for each of the $3 \mathrm{CBD}$ oils.

of the oil), the maximum level allowed in the US for hemp-derived products. We also analyzed the oils for terpene content as shown in Table 2, this information was not provided by all of the companies, and therefore, only our data are provided. The 3 oils varied in color and so chlorophyll/carotenoid content was assessed spectrophotometrically (see online suppl. Table $1[30,31]$; see www. karger.com/doi/10.1159/000510256 for all online suppl. material). Additionally, 2 of the oils (Oil B and Oil C) listed fractionated coconut oil (or medium-chain triglyceride coconut oil) on the ingredient list, while Oil A was pure hemp oil.

\section{Ability of CBD Oils to Reduce Cancer Cell Viability}

To assess the ability of the CBD oils to reduce cell viability, we conducted cell death experiments as previously described for pure CBD [13]. The oils were diluted in DMSO such that the cells were treated with $10 \mu \mathrm{M}$
CBD for each oil (oil content varied between 0.05 and $0.06 \%)$. There was again a cell-type specific effect of CBD oils to reduce cell viability observed in all 3 cancer types. Selected CBD oils were effective at reducing viability in SW480 and HCT116 CRC cells (Fig. 2a), 1205Lu melanoma cells (Fig. 2b), and T98G GBM cells (Fig. 2c), but not effective against the melanoma cell line A375M (Fig. 2b) or the GBM cell line U87MG (Fig. 2c). Interestingly, despite all the oils being diluted to the same CBD concentration, Oil A was consistently the most potent, while Oil $\mathrm{C}$ was always the least potent and never produced a statistically significant reduction in cell viability (Fig. 2). Indeed, not only was Oil $\mathrm{C}$ indistinguishable from control, Oil A was significantly better than Oil C at reducing cell viability in 4 of the 6 lines tested (statistical analysis not shown). The potency of Oil B was variable based upon cell line tested. To confirm these results, we purchased a different lot of oil from each company and found no significant differences in the ability to reduce cancer cell viability between lots (data not shown). The Oil A results were confirmed by trypan blue staining. Given the same results, these new preparations were not analyzed for CBD content.

\section{Efficacy of CBD Compared to CBD Oil}

To compare the efficacy of pure CBD compared to the most potent CBD oil preparation (Oil A), we performed dose effect experiments for each preparation based upon the CBD content. As shown, in Figure 3 and Table 3, the efficacy of CBD was generally better than that observed for Oil A; however, this difference only achieved statistical significance between pure CBD and Oil A in the CRC cell line SW480.
Raup-Konsavage/Carkaci-Salli/ Greenland/Gearhart/Vrana 
Fig. 2. The ability of $\mathrm{CBD}$ oils to reduce cancer cell viability. Cell viability was measured by MTS assay $48 \mathrm{~h}$ after treatment with CBD Oil normalized to $10 \mu \mathrm{M}$ CBD: colorectal cancer cell lines (SW480 and HCT116 cells) (a); melanoma cell lines (1205Lu and A375M) (b); and GBM cell lines (T98G, U87MG) (c). Results are normalized to DMSO vehicle. Error bars are SEM; ${ }^{*} p \leq 0.05,{ }^{* *} p \leq 0.01$. CBD, cannabidiol; GBM, glioblastoma.

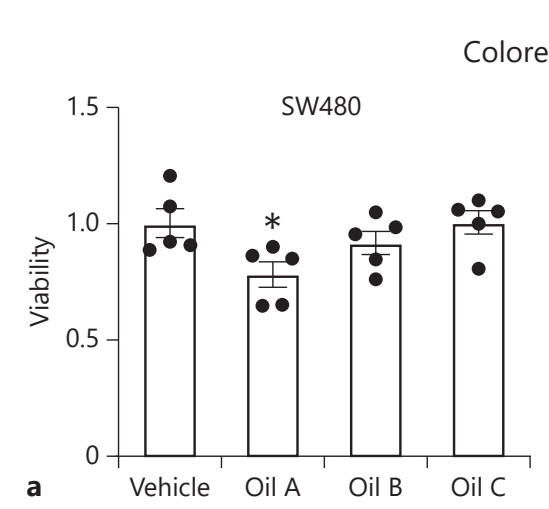

Colorectal cancer
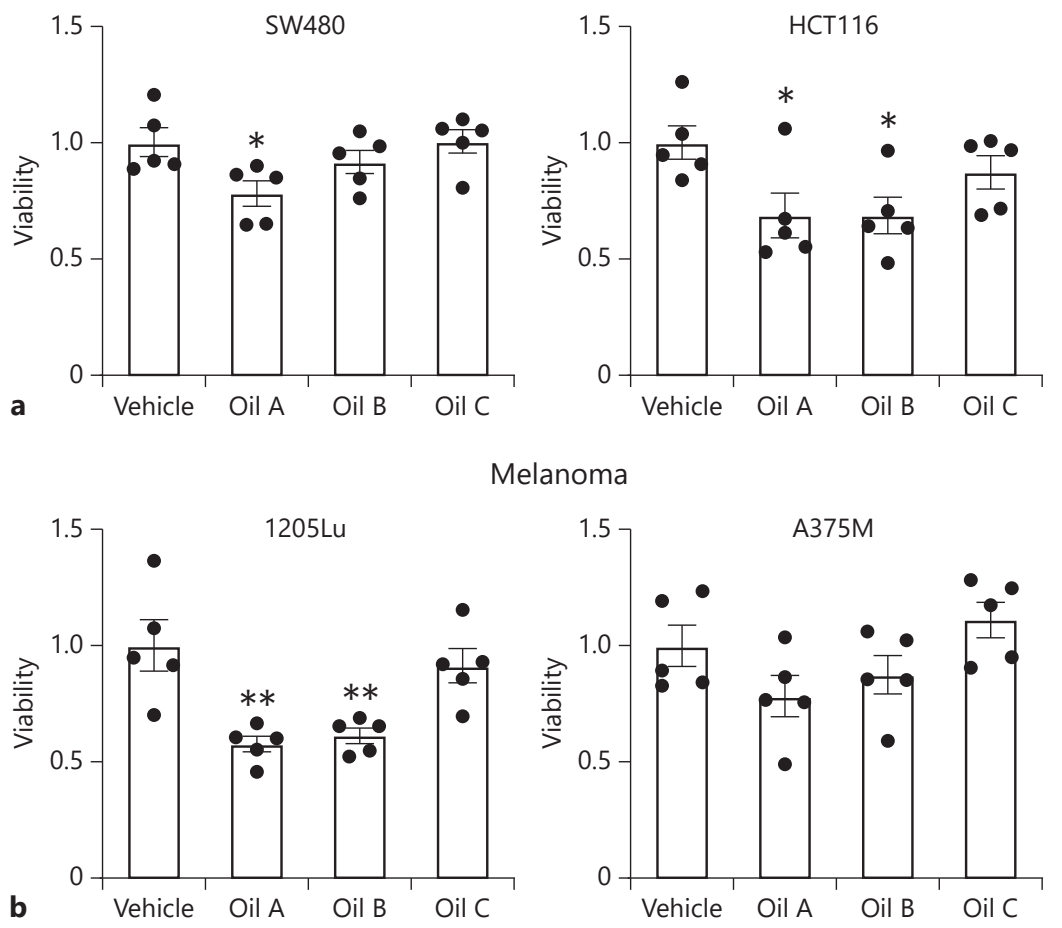

Melanoma

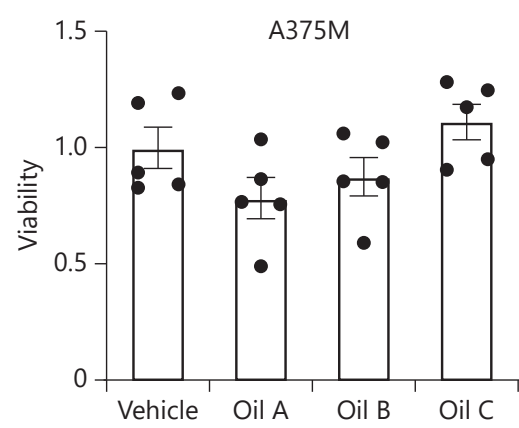

Glioblastoma
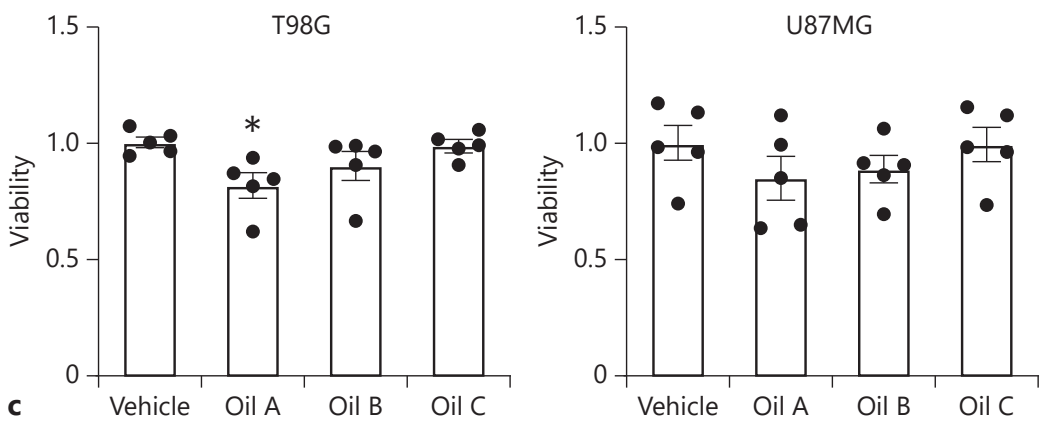

Table 3. $\mathrm{CBD}$ is more potent than $\mathrm{CBD}$ Oil A

\section{Discussion}

We did not observe an increased efficacy for the CBD oils tested compared to pure $\mathrm{CBD}$, nor a decrease in $\mathrm{IC}_{50}$ (increased pharmacological potency). These data suggest that, in reducing the viability of cancer cells in tissue culture, there is no entourage effect in this restricted area of investigation. Moreover, it further suggests that the contributions from less abundant cannabinoids and other phytochemicals are very minor (if any).

Our results - showing that there does not appear to be an entourage effect when comparing pure CBD to high

\begin{tabular}{lcc}
\hline Cell line & CBD IC50 $\mu \mathrm{m}$ & CBD Oil A IC50 $\mu \mathrm{m}$ \\
\hline SW480 & $5.8 \pm 2.6^{*}$ & $36.8 \pm 5.6$ \\
HCT116 & $8.0 \pm 4.8$ & $25.5 \pm 8.3$ \\
1,205Lu & $16.6 \pm 3.2$ & $23.5 \pm 1.7$ \\
A375M & $14.1 \pm 1.2$ & $25.1 \pm 1.6$ \\
T98G & $10.4 \pm 1.9$ & $19.1 \pm 2.7$ \\
U87MG & $17.8 \pm 1.5$ & $18 \pm 2.0$ \\
\hline
\end{tabular}

$\mathrm{CBD}$, cannabidiol. $\mathrm{IC}_{50}$ values for each of the 6 cell lines for both CBD and CBD Oil A (normalized to constant amounts of CBD). 


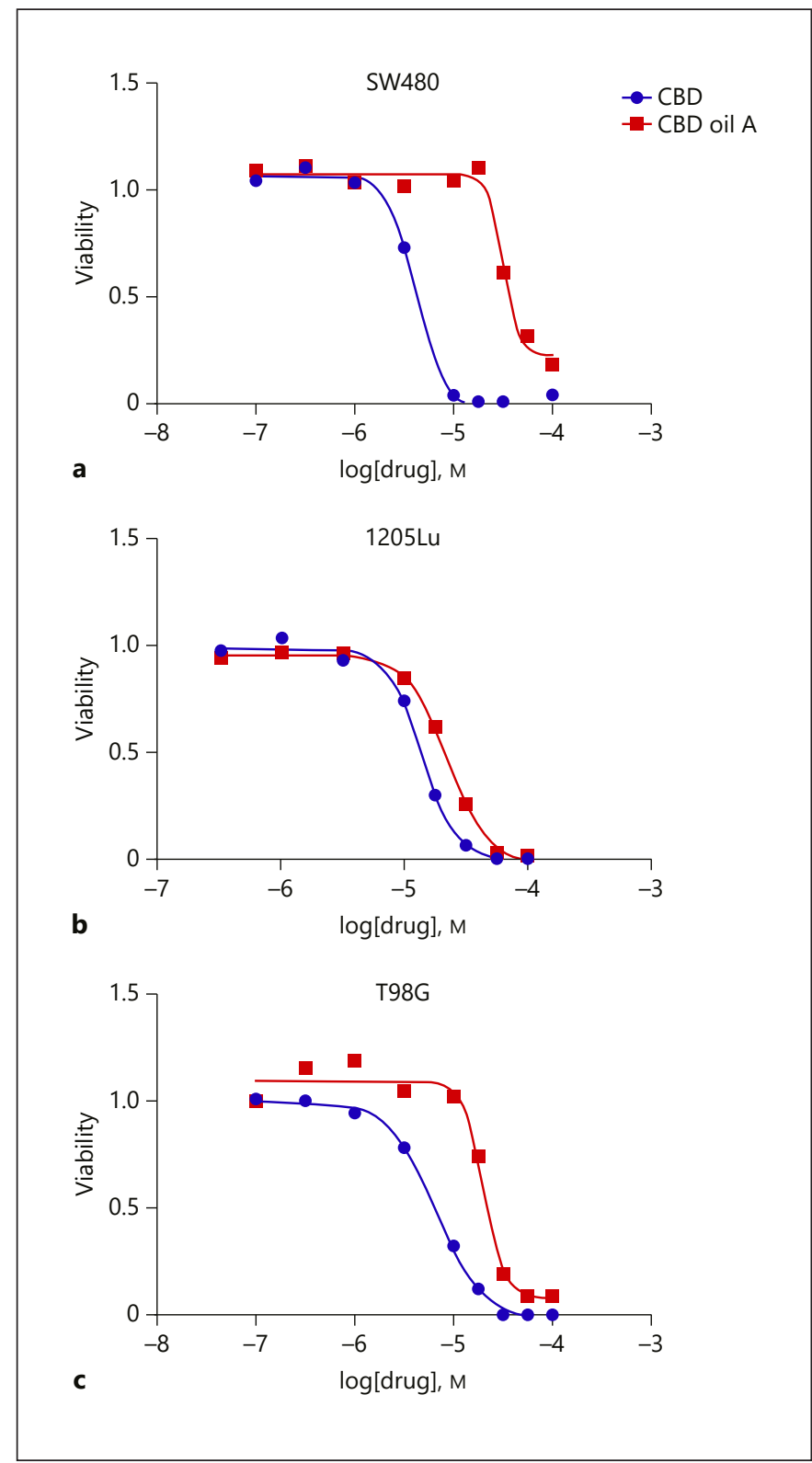

Fig. 3. Sample dose response curves for CBD compared to CBD oil A. Cell viability was measured by MTS assay $48 \mathrm{~h}$ after treatment with CBD or CBD Oil A at 100, 56, 33, 18, 10, 3.3, 1.0 $\mu \mathrm{M}, 330 \mathrm{nM}$, and 100 nM: CRC line SW480 (a); melanoma cell line 1205Lu (b); and GBM cell line T98G (c). CBD, cannabidiol; CRC, colorectal cancer cell; GBM, glioblastoma.

CBD content hemp oils - are in contrast to a recent study in breast cancer cells that showed botanical drug preparations were more efficacious than pure THC at reducing cell viability [32]. We also conducted an experiment in which CRCs were treated with equal amounts of CBD and THC in media containing serum and did not see any further enhancement of the toxic effect of CBD alone (data not shown). However, there are several differences between our study and the study of Blasco-Benito and colleagues [32]. First, our study did not serum-starve cells, and this likely accounts for the difference in findings. Cannabinoids have been found to be greater than $90 \%$ bound to protein in blood samples from human pharmacokinetic experiments and so, in the absence of plasma proteins, the effective concentration of free drug will be much higher. In the present study, we chose to avoid serum starvation because it less accurately reflects the human system and renders the cells more fragile and sensitive to drug treatment [33-36]. Second, the 2 studies examined different principal cannabinoids; here, we examined the effect around CBD oil and attendant additional phytochemicals, and the former study focused on THC. Interestingly, their plant extract did not contain any CBD [32]. We have not observed an ability of pure THC to reduce viability in CRC cells [13], nor melanoma or GBM cells (data not shown). Several studies have reported that THC can reduce cancer cell viability; however, these studies were all performed in low or no serum conditions $[10,19,21,22]$. In agreement with these studies, we did find that THC can reduce cell viability in CRCs to levels similar to CBD under no serum conditions (data not shown) and so, our findings are not in conflict. However, in the presence of serum, we do not see an effect of THC, and this is in agreement with a study that showed that cell viability of cancer cells in serum was not impacted by THC at concentrations less than $63.5 \mu \mathrm{M}[37]$.

Another interesting finding from this study is that Oil $\mathrm{C}$ appeared to protect cancer cells from the toxic effects of CBD (Fig. 2), particularly when compared to Oil A. That is, even though they contained identical levels of $\mathrm{CBD}$, Oil A was comparable in restricting cancer cell viability to pure CBD, while Oil C was without effect. Examination of the analyzed cannabinoid and terpenoid content of Oil C compared to Oils A and B did not reveal any notable differences in composition that could be potential chemical entities that could be the cause of this protection, and further analysis of the composition of Oil $\mathrm{C}$ will be required. This finding does highlight the difference between utilizing a pure compound versus a botanical extract.

A number of recent studies have highlighted that not all CBD oils are in agreement with their labels. With regard to CBD oil composition our findings is in agreement with a study by Urasaki et al. [38] that found oil composition in agreement with the manufacturer's label. This is 
in contrast with other studies that have shown marked differences between the actual composition of CBD oil and what is stated on the label $[39,40]$. This highlights a concern that, in this unregulated commercial environment, $\mathrm{CBD}$ composition is highly variable and that there is a need for regulatory control and government-sanctioned independent testing of commercial products. Additionally, the findings from Urasaki and colleagues regarding the ability of pure CBD versus $\mathrm{CBD}$ oils to downregulate $\mathrm{PI} 3 \mathrm{~K} / \mathrm{Akt} / \mathrm{mTOR}$ signaling in neuronal cells, parallel our results in that pure hemp oil (Oil A) was more potent in their studies than hemp oil that was diluted in coconut oil (Oils B and C) [38].

In summary, we found that no $\mathrm{CBD}$ oil was more potent than pure $\mathrm{CBD}$ at reducing cancer cell viability and, in fact, at least 1 oil was consistently less efficacious. It is important to recognize that this is a narrow application of using CBD oils to reduce cancer cell viability in culture. We do not suggest that there are no synergistic effects of CBD oil in other clinical settings. However, the findings do speak to the need to empirically examine the possibility for "entourage" effects before drawing conclusions. Moreover, the variability in composition and activities of botanical extracts highlights the difficulties in assessing their therapeutic potential compared to pure (or highly purified) chemical entities.

\section{Acknowledgements}

We thank the Penn State University College of Medicine Drug Discovery, Development, and Delivery Core for assisting with these experiments. We also thank Dr. Gregory Yochum for the CRC cell lines, Dr. Sang Lee for the GBM cell lines, Dr. Arun Sharma for the A375M cell line, and Dr. Manoj Pandey for the 1205Lu cell line. This work was supported by an unrestricted sponsored research agreement from Pennsylvania Options for Wellness (a state-approved medical marijuana clinical registrant).

\section{Statement of Ethics}

The paper is exempt from ethical committee approval because no animal or human subjects were used in this study.

\section{Conflict of Interest Statement}

K.E.V. and the Penn State College of Medicine are the recipients of research support from PA Options for Wellness (a stateapproved medical marijuana clinical registrant). The funding source had no involvement in study design, data collection, analysis, and interpretation; writing of the report; or the decision to submit the article for publication. K.G. and R.G. Jr. are employees of Keystone State Testing, LLC (a Pennsylvania-approved medical marijuana testing laboratory). There are no other conflicts of interest or competing financial interests to disclose.

\section{Funding Sources}

K.E.V. and the Penn State College of Medicine are the recipients of research support from PA Options for Wellness a Pennsylvania-approved medical marijuana clinical registrant and Penn State College of Medicine is a Pennsylvania-approved Academic Clinical Research Center.

\section{Author Contributions}

Experiments were designed by N.C.S., W.M.R.K., and K.E.V. and conducted by N.C.S. and W.R.M.K. Analysis of CBD oil composition was performed by K.G. \& R.G. The manuscript was written by W.M.R.K. and revised and approved by N.C.S., K.G., R.G., and K.E.V.

\section{References}

1 Ambrose T, Simmons A. Cannabis, cannabinoids, and the endocannabinoid system-is there therapeutic potential for inflammatory bowel disease? J Crohns Colitis. 2019 Mar; 13(4):525-35.

2 Burstein S. Cannabidiol (CBD) and its analogs: a review of their effects on inflammation. Bioorg Med Chem. 2015 Apr;23(7):1377-85.

3 Hammell DC, Zhang LP, Ma F, Abshire SM, McIlwrath SL, Stinchcomb AL, et al. Transdermal cannabidiol reduces inflammation and pain-related behaviours in a rat model of arthritis. Eur J Pain. 2016 07;20(6):936-48.

4 Philpott HT, O'Brien M, McDougall JJ. Attenuation of early phase inflammation by cannabidiol prevents pain and nerve damage in rat osteoarthritis. Pain. 2017 Dec;158(12): 2442-51.

5 Pharmaceuticals U. Marinol. New drug application. Food and Drug Administration: FDA; 2004.

6 Pharmaceuticals V. Cesamet. New drug application. Food and Drug Administration: FDA; 2006.

7 Navari R. Management of chemotherapy-induced nausea and vomiting: focus on newer agents and new uses for older agents. Drugs. 2013;73(3):249-62.

8 Argilés JM, Busquets S, Stemmler B, LópezSoriano FJ. Cancer cachexia: understanding the molecular basis. Nat Rev Cancer. 2014 Nov;14(11):754-62.
9 Pharmaceuticals G. Epidiolex. New drug application. Food and Drug Administration: FDA; 2018

10 Greenhough A, Patsos HA, Williams AC, Paraskeva C. The cannabinoid delta(9)-tetrahydrocannabinol inhibits RAS-MAPK and PI3K-AKT survival signalling and induces BAD-mediated apoptosis in colorectal cancer cells. Int J Cancer. 2007 Nov;121(10):217280.

11 Borrelli F, Pagano E, Romano B, Panzera S, Maiello F, Coppola D, et al. Colon carcinogenesis is inhibited by the TRPM8 antagonist cannabigerol, a cannabis-derived non-psychotropic cannabinoid. Carcinogenesis. 2014 Dec;35(12):2787-97. 
12 Pellerito O, Notaro A, Sabella S, De Blasio A, Vento R, Calvaruso G, et al. WIN induces apoptotic cell death in human colon cancer cells through a block of autophagic flux dependent on PPAR $\gamma$ down-regulation. Apoptosis. 2014 Jun;19(6):1029-42.

13 Raup-Konsavage WM, Johnson M, Legare CA, Yochum GS, Morgan DJ, Vrana KE. Synthetic cannabinoid activity against colorectal cancer cells. Cannabis Cannabinoid Res. 2018;3(1):272-81.

14 Ben-Shabat S, Fride E, Sheskin T, Tamiri T, Rhee MH, Vogel Z, et al. An entourage effect: inactive endogenous fatty acid glycerol esters enhance 2-arachidonoyl-glycerol cannabinoid activity. Eur J Pharmacol. 1998 Jul; 353(1):23-31.

15 Russo EB. Taming THC: potential cannabis synergy and phytocannabinoid-terpenoid entourage effects. Br J Pharmacol. 2011 Aug; 163(7):1344-64.

16 Russo EB. Beyond cannabis: plants and the endocannabinoid system. Trends Pharmacol Sci. 2016 Jul;37(7):594-605.

17 Bonn-Miller MO, ElSohly MA, Loflin MJE, Chandra S, Vandrey R. Cannabis and cannabinoid drug development: evaluating botanical versus single molecule approaches. Int Rev Psychiatry. 2018 06;30(3):277-84.

18 Russo EB. The case for the entourage effect and conventional breeding of clinical cannabis: no "Strain," no gain. Front Plant Sci. 2018; 9:1969.

19 Caffarel MM, Sarrió D, Palacios J, Guzmán M, Sánchez C. Delta9-tetrahydrocannabinol inhibits cell cycle progression in human breast cancer cells through $\mathrm{Cdc} 2$ regulation. Cancer Res. 2006 Jul;66(13):6615-21.

20 Ligresti A, Moriello AS, Starowicz K, Matias I, Pisanti S, De Petrocellis L, et al. Antitumor activity of plant cannabinoids with emphasis on the effect of cannabidiol on human breast carcinoma. J Pharmacol Exp Ther. 2006 Sep; 318(3):1375-87.

21 Salazar M, Carracedo A, Salanueva IJ, Hernández-Tiedra S, Lorente M, Egia A, et al. Cannabinoid action induces autophagy-mediated cell death through stimulation of ER stress in human glioma cells. J Clin Invest. 2009 May;119(5):1359-72.
22 Marcu JP, Christian RT, Lau D, Zielinski AJ, Horowitz MP, Lee J, et al. Cannabidiol enhances the inhibitory effects of delta9-tetrahydrocannabinol on human glioblastoma cell proliferation and survival. Mol Cancer Ther. 2010 Jan;9(1):180-9.

23 Solinas M, Massi P, Cinquina V, Valenti M, Bolognini D, Gariboldi M, et al. Cannabidiol, a non-psychoactive cannabinoid compound, inhibits proliferation and invasion in U87MG and T98G glioma cells through a multitarget effect. PLoS One. 2013;8(10):e76918.

24 Scott KA, Dalgleish AG, Liu WM. The combination of cannabidiol and $\Delta 9$-tetrahydrocannabinol enhances the anticancer effects of radiation in an orthotopic murine glioma model. Mol Cancer Ther. 2014 Dec;13(12): 2955-67.

25 Fonseca BM, Correia-da-Silva G, Teixeira NA. Cannabinoid-induced cell death in endometrial cancer cells: involvement of TRPV1 receptors in apoptosis. J Physiol Biochem. 2018 May;74(2):261-72.

26 Jeong S, Yun HK, Jeong YA, Jo MJ, Kang SH, Kim JL, et al. Cannabidiol-induced apoptosis is mediated by activation of Noxa in human colorectal cancer cells. Cancer Lett. 2019 04; 447:12-23.

27 Hart S, Fischer OM, Ullrich A. Cannabinoids induce cancer cell proliferation via tumor necrosis factor alpha-converting enzyme (TACE/ADAM17)-mediated transactivation of the epidermal growth factor receptor. Cancer Res. 2004 Mar;64(6):1943-50.

28 McKallip RJ, Nagarkatti M, Nagarkatti PS. Delta-9-tetrahydrocannabinol enhances breast cancer growth and metastasis by suppression of the antitumor immune response. J Immunol. 2005 Mar;174(6):3281-9.

29 Upton R, Craker L, ElSohly M, Romm A, Russo E, Sexton M. Cannabis inflorescence: cannabis spp.: standards of identity, analysis and quality control. Scotts Valley, CA: American Herbal Pharmacopoeia; 2013.

30 Seppanen C, Rahmani M, Csallany A. Simultaneous determination of chlorophylls, pheophytins, B-carotene, tocopherols, and tocotrienols in olive and soybean oils by high-performance liquid CHromatography. J Food Sci. 2006;68(5):1644-7.
31 Kang YR, Park J, Jung SK, Chang YH. Synthesis, characterization, and functional properties of chlorophylls, pheophytins, and $\mathrm{Zn}$ pheophytins. Food Chem. 2018 Apr;245:94350.

32 Blasco-Benito S, Seijo-Vila M, Caro-Villalobos M, Tundidor I, Andradas C, GarcíaTaboada E, et al. Appraising the "entourage effect": antitumor action of a pure cannabinoid versus a botanical drug preparation in preclinical models of breast cancer. Biochem Pharmacol. 2018 11;157:285-93.

33 Nabilone. Drug label information: DailyMed. Nabilone (cesamet). U.S. National Library of Medicine; 2015. : https://dailymed.nlm.nih. gov/dailymed/drugInfo.cfm?setid=bb582d640f51-11df-8a39-0800200c9a66.

34 Cannabidiol. Full prescribing information. Cannabidiol (epidiolex). : https://www.epidiolex.com/sites/default/files/EPIDIOLEX_ Full_Prescribing_Information.pdf2018.

35 Dronabinol. Full prescribing information. Dronabinol (marinol); 2018. : https://www. rxabbvie.com/pdf/marinol_PI.pdf.

36 Dronabinol. Full prescribing information. Dronabinol (syndros); 2018. : http://syndros. com/wp-content/uploads/2019/06/SYNDROS-label.pdf.

37 Galanti G, Fisher T, Kventsel I, Shoham J, Gallily R, Mechoulam R, et al. Delta 9-tetrahydrocannabinol inhibits cell cycle progression by downregulation of E2F1 in human glioblastoma multiforme cells. Acta Oncol. 2008;47(6):1062-70.

38 Urasaki Y, Beaumont C, Workman M, Talbot JN, Hill DK, Le TT. Potency assessment of CBD oils by their effects on cell signaling pathways. Nutrients. 2020 Jan;12(2):357.

39 Bonn-Miller MO, Loflin MJE, Thomas BF, Marcu JP, Hyke T, Vandrey R. Labeling accuracy of cannabidiol extracts sold online. JAMA. 2017 Nov;318(17):1708-9.

40 Pavlovic R, Nenna G, Calvi L, Panseri S, Borgonovo G, Giupponi L, et al. Quality traits of "Cannabidiol oils": cannabinoids content, terpene fingerprint and oxidation stability of european commercially available preparations. Molecules. 2018 May;23(5):1230. 